\section{My Telehealth Experience pre-COVID-19 and During COVID-19}

Richard J. Barohn, MD

I plunged into the telehealth world three years pre COVID out of necessity. Patients with ALS and their families from the Wichita Kansas area had difficulty driving the three and a half hours to Kansas City for our multidisciplinary specialty care clinic. Early in the disease it is not as difficult for patients to make the trip, but as the disease advances and they get progressively weaker it becomes a significant burden. Wichita is not a small city but none of the neurologist in the city would commit do to doing a multidisciplinary als clinic. They would see patients with possible ALS and refer them to Kansas City for confirmation and follow up. ALS is not a common disease. It is estimated a primary care doctor will see one als patient in their career and a general neurologists sees on average one als patient a year. On the other hand at a multidisciplanary als clinic we would see 4 or 5 new patients a week as all the patients are funneled into these clinics. ALS is such a terrifying disease to patients and families but also to providers who don't have a lot of experience with diagnosing and managing these patients. So after years of trying to convince some of the talented Wichita neurologists to take this on without success, I had the following idea. What if all new patients had to have at least once visit to the Kansas City ALS specialists to confirm the diagnosis and begin a management plan? And then all subsequent visits could be done with the patient in Wichita and me in Kansas City via zoom? I worked closely with the ALS Association chapter in the Midwest region which covers Kansas, Missouri, and Nebraska. The leadership in ALSA figured out how we could hire the health care specialists needed for a multi specialty ALS clinic in the Wichita area. These include physical therapy, occupational therapy, respiratory therapy, speech therapy, social work and a equipment vendor. All of these specialists are on site in the Kansas City ALS clinic with the neurologists when patients are seen for follow up visits. The difference in the telehealth experience was the health care providers were in Wichita but I was in Kansas City. We were able to convince a home health care company that employed most of these specialists to do home heart care visits to partner with us. The ALSA chapter provided a social worker they had on staff. The ALSA chapter also raised money from donors to pay the Wichita health care company to provide the specialists.

On Thursday mornings 4 ALS patients would come to a Wichita clinic office building we rented (again ALSA raised money for this). At 8:30 we would have a zoom huddle and go over all four patients before we saw them I also had on my team in Kansas City one of the ALS clinic nurses who was used to working with physicians that manage ALS patients Also a day or two before the scheduled visit, the ALSA social worker would call the patient and family and asked some questions about what the major issues were they wanted to talk about and gathered other clinical information. They would also obtain the ALSFRS at that time and record it so I had this to look at before the telehealth visit and I could compare it with the prior scores. They wrote this all down on a form that myself and the other health care providers had to read during the huddle. So we had a "head start." Then at 8:30 the health care providers would all go see each patient in their exam rooms. This took one and a half hours. At 10:30 I would zoom back on and I would spend about 30 minute with each patient. An iPAD would be put on a IV pole on wheels as a "head" and one of my white doctor coats would be draped over the IV pole, with a stethoscope wrapped around my neck. I was transformed into "robot ric." They wheeled me from room to room. All of the therapist would go to each patient's room as well and after some appropriate "hellos" to the patient from robot ric to break the ice I would ask a couple questions and then I would ask each therapist to report on what they discussed with the patient and we made plans for each area such as splints, walkers, wheelchairs, BIPAP, nutrition, PEG tube, communication assisted devices, medications, etc. The family was involved in the conversation on all of these issues. We would always ask questions about depression and anxiety and treat as appropriate. We would discuss "do not resuscitate" issues, power of attorney issues, and other end of life issues.

The other glitch was billing. I was able to bill a physician telehealth code. But insurers (Medicare and private insurers) still do not allow the health care providers other than physicians to bill for telehealth. This is definitely something that needs to be addressed in the health care system. In our case we could not have done this clinic withough the philanthropic support of the Midwest ALSA chapter to reimburse for the time of the providers in Wichita.

This system was amazingly well received by patients, family, and health care providers. The program achieved 
the Clinic Innovation of the Year award at the annual national ALSA meeting. Patients did not miss seeing the doctor in person. They greatly appreciated the need not to drive nearly 4 hours or longer in an uncomfortable car or van. We saw patients every three months. As the patients disease progressed, they would become weaker and as they neared the end of their journey, I developed the ability even through telehealth to sensitively say "goodbye" to the patients when I felt it may be their last clinic visit, and it usually was. At the end of each clinic visit we all felt like we had done a good thing as health care providers. We always ended the experience on a satisfaction high that we had done our job well and that the patients and families benefited in many ways

Then COVID-19 hit. We did our first Wichita ALS telehealth clinic the same way in early March. But then the clinics shut down throughout our system and indeed throughout the country. And patients did not really want to come to the clinic anyway even if it was open. So we adapted.

We began home ALS telehealth. The home health care providers often went to the patients homes to do their evaluations several days before the telehealth appointment with me and the whole team. Although sometimes they just called the patient ahead of time if they could go out to the house. The ALSA home care specialists still called the patient a couple of days ahead of time and asked the preclinical questions and did the ALSFRS. Then on the day of the telehealth clinic we would all get on zoom: the patient and family, me and all the health care providers in Wichita. We still had the "huddle" with just me and the providers but moved it to $10 \mathrm{am}$. Then at 10:30 we had 30 minute slots for each patient and all the providers would interact with the patient and me one at a time to come up with a plan moving forward. It worked amazingly well. So well I don't know if I would go back to the earlier method we began with.

I was involved in the COVID-19 ALS telehealth clinic from March to May. Then I moved to University of Missouri, Columbia to become the Executive Vice Chancellor of Health Affairs. I left the ALS telehealth clinic in good hands with my neuromuscular partners at the University of Kansas Medical Center. They are modifying the Kansas telehealth operation once again and are doing the Wichita ALS telehealth visits during their large in person ALS clinic. They are using the PT, OT, ST, RT providers in the Kansas City clinic to interact with the patient This is a new way of doing things and I look forward to hearing how ALS Telehealth Version 3 in Kansas works When I arrived in Columbia all of the clinics were on full force zoom operations as all medical clinics and practices around the country were as well. They were just learning how to do telehealth. I felt like the experienced old doc giving them my three years of experience! Now I am looking for opportunities at Mizzou to utilize the skill set I have learned and to implement ALS telehealth clinics in rural Missouri with my new partner Raghav Govindrajan

I am sure that there are a number of other ways to do these telehealth clinics that work equally well. But this experience did show me how flexible and adaptable we could be in our goal to care for patients and their families. And another lesson I learned throughout the three year process was that if the physician is motivated to make this work, you can communicate with the patient and family just as effectively as you can in person. They can tell when you are an empathetic physician via telehealth. They know you as a health care provider are interested in them and want to help. And that in the end is really what our role is all about. 